\title{
OPEN Identification of PDGFR $\alpha$-positive interstitial cells in the distal segment of the murine vas deferens
}

\begin{abstract}
Tasuku Hiroshige ${ }^{1,2}$, Kei-Ichiro Uemura ${ }^{2}$, Shingo Hirashima ${ }^{1}$, Kiyosato Hino ${ }^{1}$, Akinobu Togo ${ }^{3}$, Keisuke Ohta ${ }^{1,3}$, Tsukasa Igawa ${ }^{2}$ \& Kei-Ichiro Nakamura ${ }^{1}$

Platelet-derived growth factor receptor- $\alpha$ (PDGFR $\alpha$ )-positive interstitial cells (ICs) are widely distributed in various organs and may be involved in the motility of various tubular organs. We, for the first time, aimed to investigate the distribution, immunohistochemical characteristics, and ultrastructure of PDGFR $\alpha$-positive ICs in murine vas deferens, using confocal laser scanning microscopy, transmission electron microscopy (TEM), and immuno-electron microscopy (immuno-EM). For immunofluorescence, we used antibodies against PDGFR $\alpha$ and other markers of ICs. PDGFR $\alpha$-positive ICs were distributed widely in the lamina propria, smooth muscles, and serosal layers. Although most PDGFR $\alpha$-positive ICs labeled CD34, they did not label CD34 in the subepithelial layers. Additionally, PDGFR $\alpha$-positive ICs were in close proximity to each other, as also to the surrounding cells. TEM and immuno-EM findings revealed that PDGFR $\alpha$-positive ICs established close physical interactions with adjacent ICs. Extracellular vesicles were also detected around the PDGFR $\alpha$-positive ICs. Our morphological findings suggest that PDGFR $\alpha$-positive ICs may have several subpopulations, which can play an important role in intercellular signaling via direct contact with the IC network and the extracellular vesicles in the murine vas deferens. Further investigation on PDGFR $\alpha$ positive ICs in the vas deferens may lead to understanding the vas deferens mortility.
\end{abstract}

The vas deferens plays an important role in male ejaculation, during which the smooth muscle in the wall contract reflexively, propelling the sperm forward. This is also known as peristalsis ${ }^{1}$. Peristalsis of the vas deferens transports sperm from the epididymis to the ampulla, from which the seminal vesicle secretions of the sperm are propelled forward through the ejaculatory ducts toward the urethra, using synchronized rhythmic contractions of the smooth muscle. Therefore, the vas deferens plays a crucial role in transporting sperm in the genital organs $s^{2}$, and understanding vas deferens motility is important to revealing the mechanism of sperm transport.

In the case of gastrointestinal tract motility, which is the same smooth muscle organs as vas deferens, interstitial cells of Cajal (ICC) act as pacemakers for peristaltic movement. The ICC are c-Kit immunoreactive and have been extensively studied previously ${ }^{3-6}$. They generate spontaneous electrical depolarizations that organize contractile activity into patterns of phasic contractions and facilitate a pathway for active transmission of electrical activity in smooth muscles ${ }^{5}$. ICC can be easily identified by their unique ultrastructural feature, since they have small cell bodies and several elongated processes whose length reaches approximately $100 \mu \mathrm{m}$. They also have numerous mitochondria and caveolae, abundant intermediate filaments, a discontinuous basal lamina, moderately developed Golgi apparatus, rough and smooth endoplasmic reticula, close contact with nerve varicosities and formation of numerous gap junctions with each other and with smooth muscle cells ${ }^{7}$.

Recently, platelet-derived growth factor receptor- $\alpha$ (PDGFR $\alpha$ )-positive interstitial cells (ICs), with ultrastructural characteristics similar to those of ICC, have been reported in various organs other than the gastrointestinal tract $^{8}$. These ICs mostly do not express c-Kit. Like c-Kit, PDGFR $\alpha$ is a tyrosine-protein kinase that acts as a cell-surface receptor for certain isoforms of platelet-derived growth factors (PDGFs), and stimulates cell signaling pathways that elicit responses such as cellular growth and differentiation ${ }^{9}$. The most common theory is that they participate in intercellular signaling and may be responsible for the integration of signals from numerous

${ }^{1}$ Division of Microscopic and Development Anatomy, Department of Anatomy, Kurume University School of Medicine, Kurume 830-0011, Japan. ${ }^{2}$ Department of Urology, Kurume University School of Medicine, Kurume 830-0011, Japan. ${ }^{3}$ Advanced Imaging Research Center, Kurume University School of Medicine, Kurume 830-0011, Japan. ${ }^{\varpi}$ email: hiroshige_tasuku@med.kurume-u.ac.jp 
systems such as nervous, vascular and immune systems. In smooth muscle organs, they have been suggested to regulate smooth muscle motility ${ }^{10,11}$, as reported by physiological functional studies on human and murine colon, murine renal pelvis, and murine bladder ${ }^{12-15}$. Additionally, PDGFRa-positive ICs enable the maintenance and proper organization of the extracellular matrix and facilitates cell migration during organogenesis ${ }^{16}$. Therefore, they have a potential role in the etiopathogenesis of different diseases ${ }^{17}$. Although PDGFRa-positive ICs in the male genitalia have been reported in the testes ${ }^{18,19}$ and seminal vesicles ${ }^{20}$, they have not been investigated in the vas deferens.

Here, we aimed to identify PDGFRa-positive ICs in murine vas deferens, and characterize their morphological features, ultrastructure, and positional relationship with other tissues (smooth muscle bundles, nerve tracts, blood vessels, epithelial cells, and macrophages) using immunohistochemistry, transmission electron microscopy (TEM), and immune-electron microscopy (immune-EM) for the first time. Our results will help in understanding the potential function of PDGFRa-positive ICs and their involvement in vas deferens motility.

\section{Methods}

Animals. Three green fluorescent protein (GFP) transgenic male mice (C57BL/6-Tg (CAG-EGFP)1Osb/J) ${ }^{21}$ and three wild-type (WT) male mice $(\mathrm{C} 57 \mathrm{BL} / 6)$ were used in this study. All the mice were bred at the institution's animal facility. GFP transgenic mice and wild-type mice were sacrificed by the method described below at the age of 3-6 months. All mice were fed ad libitum and bred under a normal 12-h light/dark schedule. All the experiments were performed in accordance with the National Institutes of Health Guidelines for Animal Research and ARRIVE (Animal Research: Reporting of In Vivo Experiments) guidelines (https://www.nc3rs. org.uk/arrive-guidelines). All the animal procedures were approved by the Board for Animal Experiments of Kurume University.

Tissue clearing using the clear unobstructed brain imaging cocktails and computational analysis (CUBIC) protocol and multi-photon deep imaging. GFP transgenic male mice were anesthetized with sodium pentobarbital $(50 \mathrm{mg} / \mathrm{kg})$. The mice were then fixed in a supine position with their necks extended and were then transcardially perfused through the left ventricle with heparin containing $(10 \mathrm{U} / \mathrm{mL})$ saline, followed by fixation with $4 \%$ paraformaldehyde in phosphate buffered saline (PBS). After perfusion, a median incision was made to open the abdominal cavity to harvest bilateral pars vas deferens. The dissected specimens were immersed in the same fixative overnight at $4{ }^{\circ} \mathrm{C}$. After washing with PBS, the post-fixed specimens were immersed in 50\% CUBIC-L solution (T3740, Tokyo Chemical Industry) in distilled water on a shaker at $37^{\circ} \mathrm{C}$ overnight. Next, the specimens were immersed in $100 \%$ CUBIC-L solution on a shaker at $37^{\circ} \mathrm{C}$ for 5 days and $100 \%$ CUBIC-L solution was refreshed every other day. Following delipidation, the specimens were washed in PBS overnight at room temperature $\left(22-25^{\circ} \mathrm{C}\right)$. The specimens were then immersed in $50 \%$ CUBIC- $\mathrm{R}^{+}$solution (T3740, Tokyo Chemical Industry) in distilled water on a shaker at room temperature $\left(22-25^{\circ} \mathrm{C}\right)$ overnight, and then immersed in CUBIC- $\mathrm{R}^{+}$solution on a shaker at room temperature for an additional 1 or 2 days and later embedded in CUBIC- $\mathrm{R}^{+}$. The transparent specimens were observed under a multi-photon microscope (FVMPE-RS, Olympus, Japan) with acquisition parameters as follows: Excitation at $1000 \mathrm{~nm}$, a $10 \times 0.6 \mathrm{NA}$ SCALEVIEW-A2 immersion lens (XLPLN10XSVMP, Olympus, Japan) and an image size of $1271 \times 1272 \mu \mathrm{m}$. Image deconvolution and three-dimensional (3D) reconstruction were performed with the resulting image stacks and was analyzed using Avizo software (version 9.1.1, FEI, USA) available at https://www.fei.com/software/avizo3d/.

Hematoxylin and Eosin (H\&E) staining. Wild type male mice were deeply anesthetized and transcardially perfused with $4 \%$ PFA in PBS as previously described. Dissected specimens were immersed in the same fixative for $2 \mathrm{~h}$ at $4{ }^{\circ} \mathrm{C}$. The specimens were subsequently trimmed, washed three times for $5 \mathrm{~min}$ in PBS, and then immersed in PBS containing $30 \%$ sucrose overnight at $4^{\circ} \mathrm{C}$, after which they were frozen in optical cutting temperature (O.C.T.) compound (Tissue-Tek, Sakura Finetek, USA). Frozen blocks were cut into $4-\mu \mathrm{m}$ thick sections using a cryomicrotome (CM1950, Leica, Germany). The sections were stained with H\&E and subsequently imaged.

Immunofluorescence histochemistry and confocal laser scanning microscope (CLSM) imaging. Aforementioned cryosections $(4 \mu \mathrm{m})$ were placed on slide glasses (refer to the text of H\&E staining). The sections were incubated with either 3\% normal goat serum or 3\% normal donkey serum and $0.5 \%$ Triton X-100 in PBS for 30 min to block non-specific binding, and then incubated with primary antibodies diluted in blocking solution overnight at $4{ }^{\circ} \mathrm{C}$ (see Supplementary Table S1 online). The sections were then incubated with secondary antibodies for $1 \mathrm{~h}\left(1: 1000\right.$ dilution) at room temperature $\left(22-25^{\circ} \mathrm{C}\right)$. Alexa Fluor-488-conjugated donkey anti-goat IgG, Alexa Fluor-488-conjugated goat anti-rat IgG, Alexa Fluor-488-conjugated goat anti-chicken IgG, Alexa Fluor-568-conjugated donkey anti-rat IgG, Alexa Fluor-647-conjugated donkey anti-chicken IgG, Alexa Fluor-568-conjugated donkey anti-rabbit IgG (all 1:500 dilution; Invitrogen, USA) were used as secondary antibodies. After washes with PBS, the immunolabeled sections were mounted using PermaFluor aqueous mounting medium (PermaFluor, Thermo Scientific, USA) and were observed under a CLSM (FV1000, Olympus, Japan) with following acquisition parameters: excitation at 473 and $559 \mathrm{~nm}, \times 60$ water immersion lens (NA=1.2), image size $=105 \times 105 \mu \mathrm{m}$.

Transmission electron microscopy (TEM). Wild type male mice were deeply anesthetized and transcardially perfused with half Karnovsky fixative (2\% paraformaldehyde, $2.5 \%$ glutaraldehyde, $2 \mathrm{mM} \mathrm{CaCl}_{2}$ in $0.1 \mathrm{M}$ cacodylate buffer [pH 7.3]) as previously described. Dissected specimens, cut into 1-mm cubes, were immersed in the same fixative for $2 \mathrm{~h}$ at $4^{\circ} \mathrm{C}$ as a post-fixation and were washed in $0.1 \mathrm{M}$ cacodylate buffer three 
times for $10 \mathrm{~min}$ each. Next, the specimens were prepared according to the en bloc stain procedure as follows: the specimens were post-fixed for $2 \mathrm{~h}$ in a solution containing $2 \%$ osmium tetraoxide and $1.5 \%$ potassium ferrocyanide in $0.2 \mathrm{M}$ cacodylate buffer at $4{ }^{\circ} \mathrm{C}$, and were then washed three times with distilled water. They were then treated in $1 \%$ aqueous thiocarbohydrazide solution for $1 \mathrm{~h}$, and immersed in a solution containing $2 \%$ osmium tetroxide in distilled water after five washes with distilled water. Later, they were washed three times with distilled water. The specimens were immersed in $4 \%$ uranyl acetate in distilled water overnight and were then washed five times with distilled water. The specimens were then stained using Walton's lead aspartate solution for $1 \mathrm{~h}^{22}$, and dehydrated using ice-chilled ethanol gradient series $(20 \%, 50 \%, 70 \%, 80 \%, 90 \%$, and twice in $100 \%$ for $10 \mathrm{~min}$ each) and ice-chilled $100 \%$ acetone for $10 \mathrm{~min}$. Dehydrated specimens were embedded by infiltration with epoxy resin (Epon 812, TAAB, England) mixture, and were polymerized for $72 \mathrm{~h}$ at $60{ }^{\circ} \mathrm{C}$. The surfaces of the specimens were exposed by trimming, and ultrathin sections with a thickness of $60 \mathrm{~nm}$ were cut from embedded specimens using a diamond knife on an ultramicrotome (Ultracut E microtome, Reichert-Jung, Germany). They were placed on copper-coated grids. The ultrathin sections on the grids were observed using a TEM (H-7000, Hitachi high technology, Japan) and were photographed using a high-resolution 16 mega-pixel digital camera (Advanced Microscopy Techniques, USA) connected to the TEM.

Post-embedding immune-electron microscopy (immuno-EM). Wild type male mice were deeply anesthetized and sodium pentobarbital $(50 \mathrm{mg} / \mathrm{kg})$ and were transcardially perfused through the left ventricle with heparin containing $(10 \mathrm{U} / \mathrm{mL})$ saline, followed by fixation with $4 \%$ paraformaldehyde (PFA) $/ 0.1 \%$ glutaraldehyde in $0.1 \mathrm{M}$ cacodylate buffer ( $\mathrm{pH} 7.3$ ). After fixation, the specimens were rinsed with $0.1 \mathrm{M}$ cacodylate buffer ( $\mathrm{pH} 7.3$ ). They were subsequently dehydrated in an ethanol series (50\%, 70\%, and $90 \%$ for $30 \mathrm{~min}$ each). Finally, the tissues were embedded in LR white and polymerized at $60^{\circ} \mathrm{C}$ for $24 \mathrm{~h}$. Post-embedding, immunogold labeling was performed as previously outlined by Valtschanoff et al. ${ }^{19}$. The surfaces of the embedded specimens were exposed, and ultrathin sections $(70 \mathrm{~nm}$ ) were cut using a diamond knife on an ultramicrotome (Ultracut E microtome, Reichert-Jung, Germany) and collected on nickel mesh grids to preserve the cutting order. After washing with PBS, the grids were blocked with $1 \%$ bovine serum albumin in $0.05 \mathrm{M}$ Tris-buffered saline with $0.5 \%$ triton X-100 (TBS-T, pH 7.6), followed by overnight treatment with goat anti-PDGFRa (1:100 dilution; catalog no. AF1062; R\&D systems, USA) diluted in blocking solution overnight at $4{ }^{\circ} \mathrm{C}$. Grids were subsequently treated with a secondary antibody conjugated to gold colloids with $10 \mathrm{~nm}$ mean particle size (1:100 dilution; catalog no. EMRAG10; BBInternational, UK). After immunoprocessing, the sections were post-stained using uranyl acetate and Sato's lead salts. The grids were examined under a TEM (H-7000, Hitachi high technology, Japan) and photographed using a high-resolution 16 mega-pixel digital camera (Advanced Microscopy Techniques, USA) connected to the TEM.

\section{Results}

Multi-photon microscopic observations of the wholemount murine vas deferens using CUBIC. We performed tissue clearing of murine vas deferens using the CUBIC method and observed the transparent wholemount vas deferens using multi-photon microscopy (see Supplementary Fig. S1 online). The observed two-dimensional (2D) images of each segment were reconstructed in 3D (Fig. 1a,e,i). The proximal segment of murine vas deferens, which was about a quarter of the entire length, had a thin lamina propria and the lumen was highly distended (Fig. 1b-d). From the proximal segment to the central portion, longitudinal folds were observed (Fig. 1f,h), and the lumen gradually narrowed (Fig. 1g). The transverse folds appeared at equal intervals and extended straight towards one another (Fig. 1f,h). In the distal segment from the center part to the ampulla, the number of longitudinal, and transverse folds and the length of the longitudinal folds increased, and the lumen became narrower (Fig. 1k,1). The mucosa between the longitudinal folds extended like a sine curve as the transverse folds intersected with one another (Fig. 1j, right upper square). Our results showed that the distal segment, containing several folds, complex lumen, and this smooth muscle layer, was the identification target.

H\&E staining. We identified several cells that had small cell bodies and elongated cellular processes in crosssectional images of $\mathrm{H} \& \mathrm{E}$ stained murine vas deferens (Fig. 2a). These cells were organized in the lamina propria (Fig. 2b, black arrows), in the smooth muscle and the serosal layers (Fig. 2c, black arrows).

CLSM observation of immunofluorescence. Immunoreactivities of all the markers (PDGFR $\alpha$, CD34, and vimentin) in labeling ICs were observed in the entire lamina propria and in between the layer of smooth muscle bundles (Fig. 2d-f). In addition, two to three layers of these immunoreactivities were observed outside the smooth muscle layer (Fig. 2d-f).

In double immunolabeling for PDGFRa and CD34 (Fig. 3a-f), PDGFRa-immunoreactivity (IR) observed beneath the epithelium was not co-labeled with CD34-IR (Fig. 3c, right upper square). PDGFRa-IR observed in deeper portions within the lamina propria in the smooth muscle layer and the serosal layer was co-labeled with CD34-IR (Fig. 3c,f). In double immunolabeling for PDGFR $\alpha$ and vimentin (Fig. 3g-1), PDGFR $\alpha$-IR was partially co-labeled with vimentin-IR in all the layers (Fig. 3i,l). The PDGFRa-IR homogeneously labeled cell bodies and cell processes, whereas vimentin-IR primarily labeled the cytoplasm and partially labeled the cell processes (Fig. 3i,l). The vimentin-single IR was frequently observed in the lamina propria (Fig. 3i). In double immunolabeling for vimentin and laminin (see Supplementary Fig. S2a online), the vimentin-IR was enclosed by laminin-IR, indicating the presence of a basal membrane of vascular endothelial cells. Therefore, the vimentinsingle IR was considered to be a different type of mesenchymal cells, including the vascular endothelial cells. Vimentin-single IR was also observed in the outermost serosal layer and could be considered as mesothelial cells (Fig. 3l, right upper square, see Supplementary Fig. S2b online). 

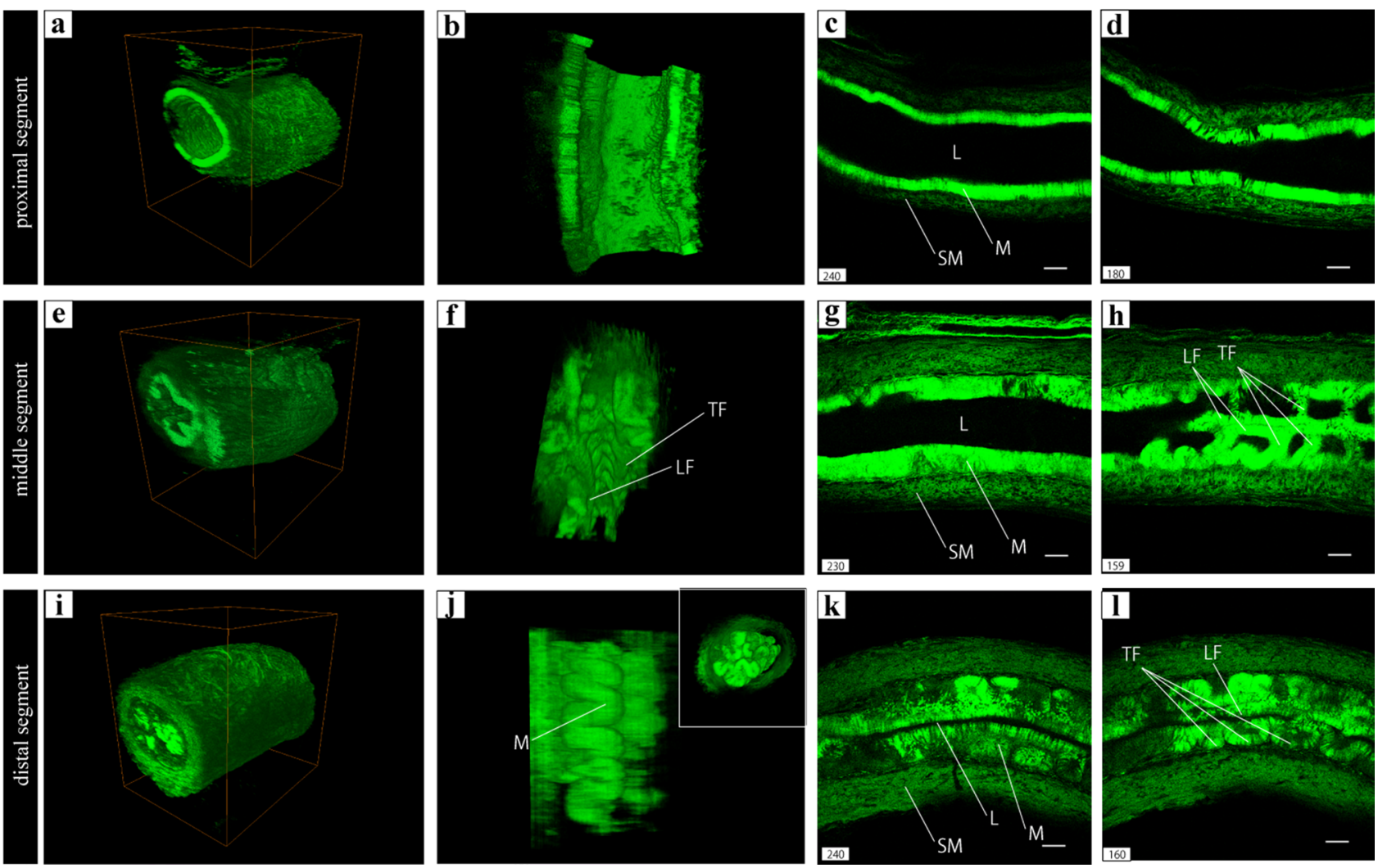

Figure 1. (a) The 3D reconstructed overview of the proximal segment of GFP transgenic murine vas deferens. (b) Lumens of (a). (c,d) Sagittal sections including the lumen of (a). (e): 3D reconstructed overview of the middle segment of GFP transgenic murine vas deferens. (f) Lumens of (e). (g,h) Sagittal sections including the lumen of (e). (i): 3D reconstructed overview of the distal segment of GFP transgenic murine vas deferens. (j): Side view of the mucosa area of (i). Front view of the mucosa area of (i) (inset at the upper right corner of $(\mathbf{j}))$. (k,l): Sagittal sections including the lumen of (i). The same images following deconvolution and 3D reconstruction using the Avizo software (version 9.1.1) available at https://www.fei.com/software/avizo3d/ $(\mathbf{a}, \mathbf{b}, \mathbf{e}, \mathbf{f}, \mathbf{i}, \mathbf{j}) . L F$ longitudinal fold, $T F$ transverse fold, $M$ mucosa, $L$ lumen, $S M$ smooth muscle. Scale bars: $100 \mu \mathrm{m}$ $(\mathbf{c}, \mathbf{d}, \mathbf{g}, \mathbf{h}, \mathbf{k}, \mathbf{l})$.

Furthermore, double immunolabeling for PDGFRa and caveolin-1 shows PDGFRa-IR was partially colabeled with caveolin-1-IR in all the layers (Fig. 4a-f). Caveolin-IR was observed heterogeneously in PDGFR $\alpha$-IR (Fig. 4f, right upper square). The distribution pattern of the caveolin-1-single IR observed in the lamina propria was consistent with the localization of vascular endothelial cells, such as vimentin-single IR (Fig. 4c). The distribution pattern of caveolin-1-single IR observed in the smooth muscle layer was consistent with the localization of smooth muscle cells (see Supplementary Fig. S2c online). Double immunolabeling for PDGFRa and connexin-43 was performed to observe gap junction mediated cellular signaling network (Fig. 4g-1). Connexin 43-IR was observed surrounding PDGFRa-IR in the lamina propria (Fig. 4i). However, connexin 43-IR was less prominent in the smooth muscle layers than in the lamina propria (Fig. 4l, white arrows).

To observe the relationship between PDGFRa-IR and other type of cells, double immunolabeling for PDGFRa and $\alpha$-smooth muscle actin ( $\alpha$ SMA, smooth muscle cells), $\beta 3$-tubulin (nerves), or ionized calcium-binding adaptor molecule 1 (Iba-1, macrophages) was performed. PDGFR $\alpha$-IR was found around vascular smooth muscle cells labeled with aSMA-IR in the lamina propria (Fig. 5a). In the smooth muscle layer, vascular smooth muscle cells were indistinguishable from smooth muscle cells of the vas deferens (Fig. 5b). Nerves labeled with $\beta 3$-tubulin were found in close proximity to some PDGFRa-IR in the lamina propria and smooth muscle layer (Fig. 5c,d). Macrophages labeled with Iba-1 were also found in close proximity to PDGFRa-IR in the lamina propria and smooth muscle layer (Fig. 5e,f). Finally, we attempted to perform double immunolabeling to examine whether c-Kit-IR, which labels ICC in the gastrointestinal tract, was observed. c-Kit-IR was only observed in mast celllike cells (Fig. 5g,h). As a positive control, we also processed the tunica muscularis of the murine colon using the same protocols as the studies on vas deferens. c-Kit-IR was observed routinely in the ICC of the colon (see Supplementary Fig. S2d online). These data verified the suitability of the antibodies and techniques used in the present study to detect c-Kit-IR.

To evaluate the expression of $\mathrm{Ca}^{2+}$-activated $\mathrm{K}^{+}(\mathrm{SK} 3)$ and $\mathrm{Ca}^{2+}$-activated $\mathrm{Cl}^{-}$(ANO-1) channels, which have been previously reported in PDGFRa-positive ICs of other smooth muscle organs ${ }^{12-14}$, in PDGFRa-positive ICs of the smooth muscle layer of the murine vas deferens, we double immunostained for PDGFRa and SK3, and 

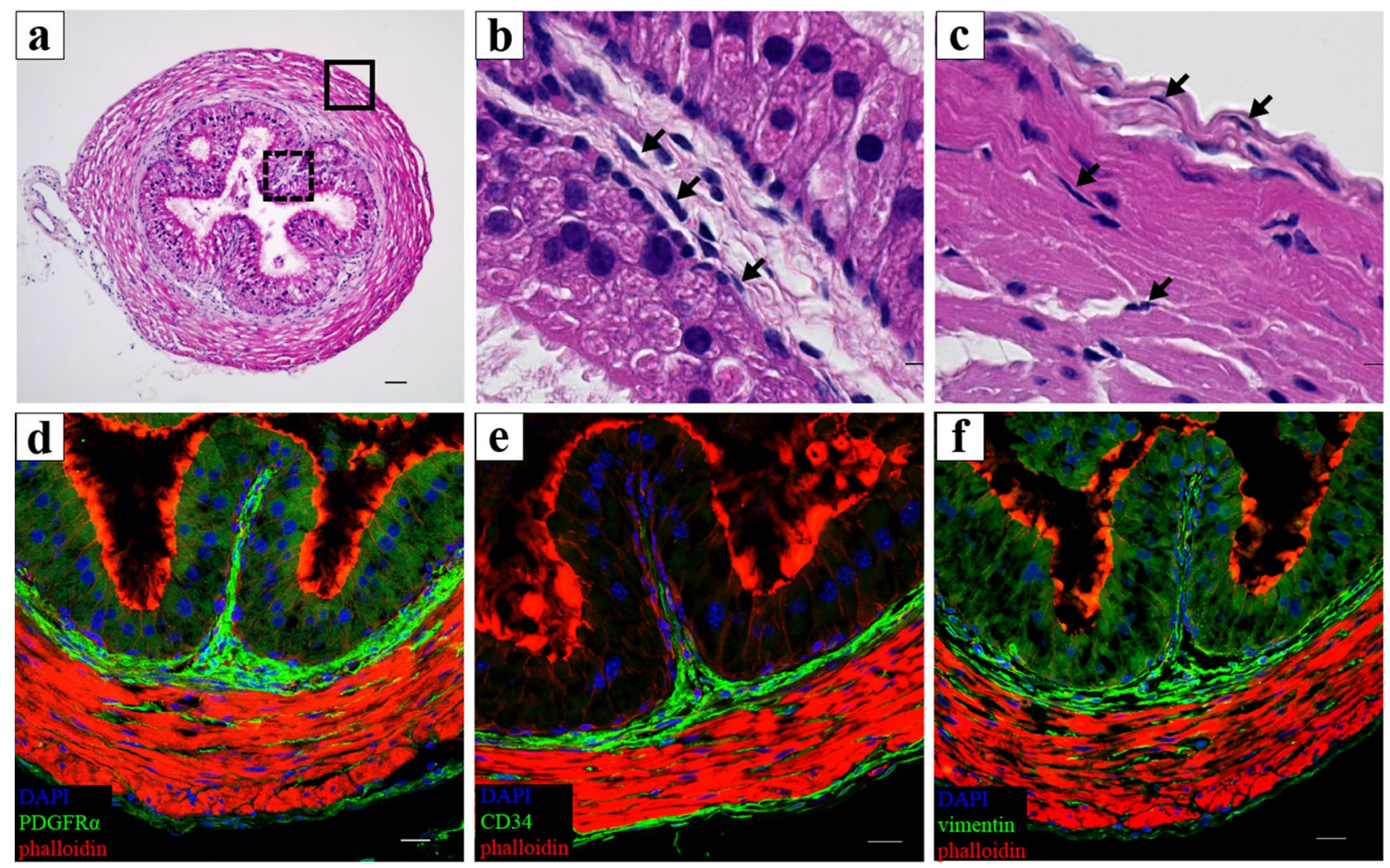

Figure 2. (a) The cross-sectional images of Hematoxylin and Eosin stained murine vas deferens. (b) High magnification of the solid black line square area of (a). Several cells with small cell bodies and elongated cellular processes were observed in the lamina propria (b, black arrows). (c) High magnification of the dotted black square area. These cells were broadly distributed in the smooth muscle and serosal layers (c, black arrows). (d) Representative image of the double immunolabeling for PDGFRa (green) and phalloidin (red). (e) Representative image of the double immunolabeling for CD34 (green) and phalloidin (red). (f) Representative image of double immunolabeling for vimentin (green) and phalloidin (red). Nuclei were counterstained in blue with 4',6-diamidino-2-phenylindole (d-f). Immunoreactivities of all the markers observed in the lamina propria, the smooth muscle and the serosal layers (d-f). Scale bars: $50 \mu \mathrm{m}(\mathbf{a}, \mathbf{d}-\mathbf{f}), 5 \mu \mathrm{m}(\mathbf{b}, \mathbf{c})$.

for PDGFRa and ANO-1, and found that PDGFRa-IR was not co-labeled with SK3-IR and ANO-1-IR (data not shown).

Ultrastructural characterization of interstitial tissue of murine vas deferens using TEM. We identified ICs in the lamina propria, smooth muscle layer, and serosal layer of murine vas deferens (Fig. 6a-f). ICs' cell bodies are relatively small, with sparse cytoplasm containing several mitochondria surrounding the nucleus (Fig. 6a-f, white arrows). ICs in all layers were close proximity to each other (Fig. 6a-c,e, black arrows). These ICs had several elongated cellular processes. Within the cellular processes, dilated and thinned segments were observed. Organelles including mitochondria were observed in the dilated segments and the cytoplasm of these cells was not surrounded by a continuous basal lamina (Fig. 6b,d,f). A small number of caveolae were partially observed in the cytoplasm of ICs in all layers (Fig. 6b,d,f, black arrowheads). This was consistent with the immunolabeling results.

ICs in all layers were in close proximity to not only each other but also the epithelium, nerves, vascular endothelial cells, and macrophages (Fig. 7a-c, black arrows), similar to the immunolabeling results. Moreover, the IC in the lamina propria was in close proximity to the epithelium (Fig. 7d, black arrow), a vascular endothelial cell (Fig. 7d, black arrowhead), and a nerve (Fig. 7d, white arrow). The IC in the smooth muscle layer was in close proximity to a smooth muscle cell (Fig. 7e, black arrow) and a nerve (Fig. 7e, black arrowhead).

Electron-dense lines were observed in the close proximity areas between the ICs (Fig. 7f,g, black arrows). These structures were not observed in close proximity areas between ICs and surrounding tissues, epithelial cells, smooth muscle cells and nerves. In addition, microvesicle-like structures or exosomes were frequently observed between ICs and surrounding tissues (Figs. 6d; 7c,e, red arrowheads).

Ultrastructural identification of PDGFR $\alpha$-IR using immuno-EM. Immuno-EM revealed that PDGFRa-IR correlated with ICs observed by TEM and confocal laser scanning microscopy with respect to their anatomical location, relative density, and approximate characteristics of the morphology. ICs of murine vas deferens were identified as PDGFRa-IR labeled with $10 \mathrm{~nm}$ colloidal golds (Fig. 8a,c); $10 \mathrm{~nm}$ colloidal golds 

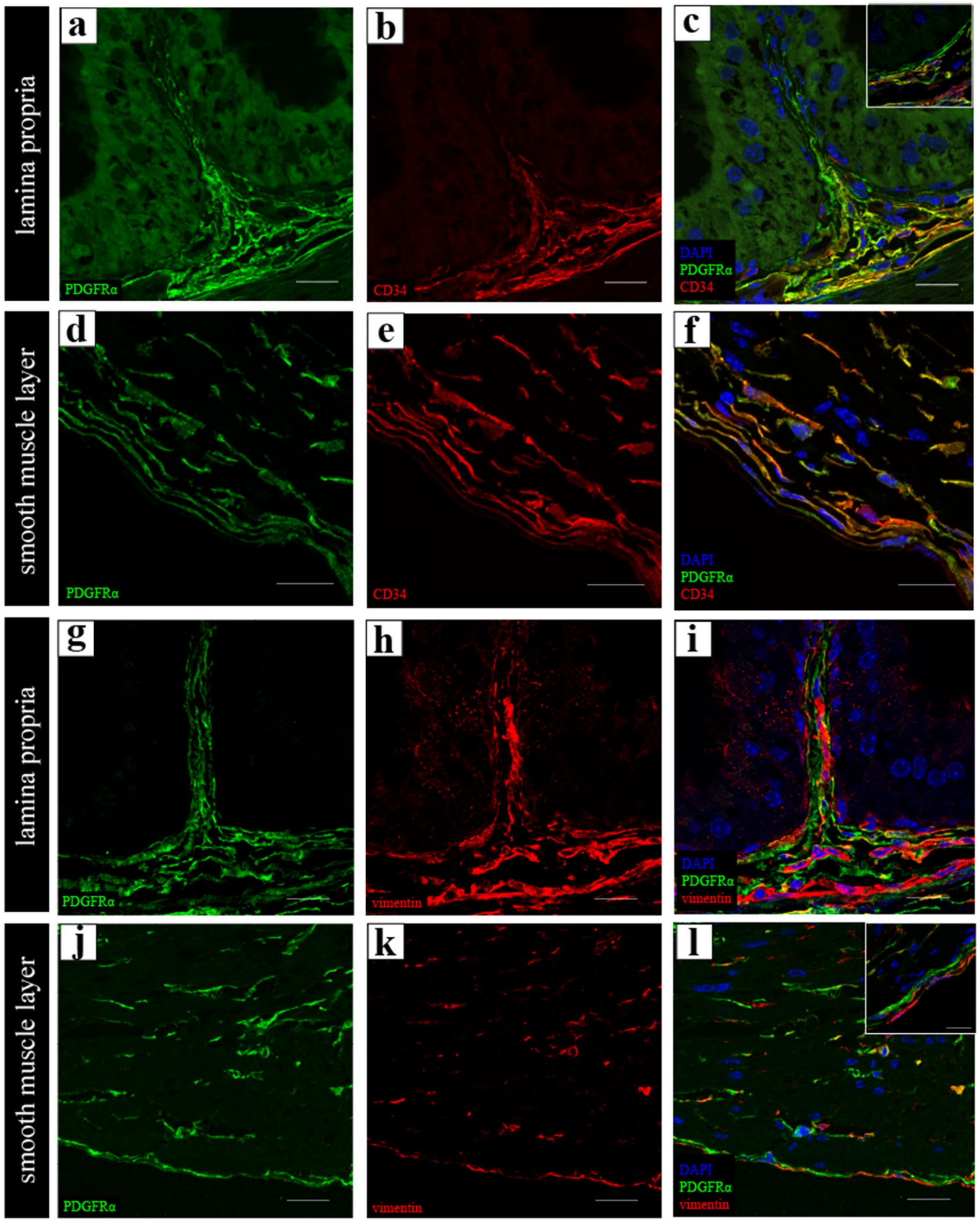

Figure 3. (a-f) Representative images of the double immunolabeling for PDGFRa (green) and CD34 (red) in the lamina propria (a-c) and in the smooth muscle layer (d-f). High magnification in the area beneath the epithelium (inset at the upper right corner of (c)). PDGFRaimmunoreactivity (IR) observed beneath the epithelium was not co-labeled with CD34-IR (c). PDGFRa-IR observed within the deeper portions of the lamina propria, in the smooth muscle and serosal layers were co-labeled with CD34 (c,f). (g-l) Representative images of the double immunolabeling for PDGFR $\alpha$ (green) and vimentin (red) in the lamina propria (g-i), in the smooth muscle layer and serosal layer $(\mathbf{j}-\mathbf{l})$. PDGFRa-IR was partially co-labeled with vimentin-IR in all layers $(\mathbf{c}, \mathbf{f})$. High magnification in the serosal layer (inset at the upper right corner of (l)). Vimentin-single IR cells were observed in the outermost of serosal layer (f). Nuclei were counterstained in blue with 4',6-diamidino-2-phenylindole (c,f,i,l). Scale bars: $20 \mu \mathrm{m}(\mathbf{a}-\mathbf{l}), 5 \mu \mathrm{m}$ (inset at the upper right corner of (c,l)). 

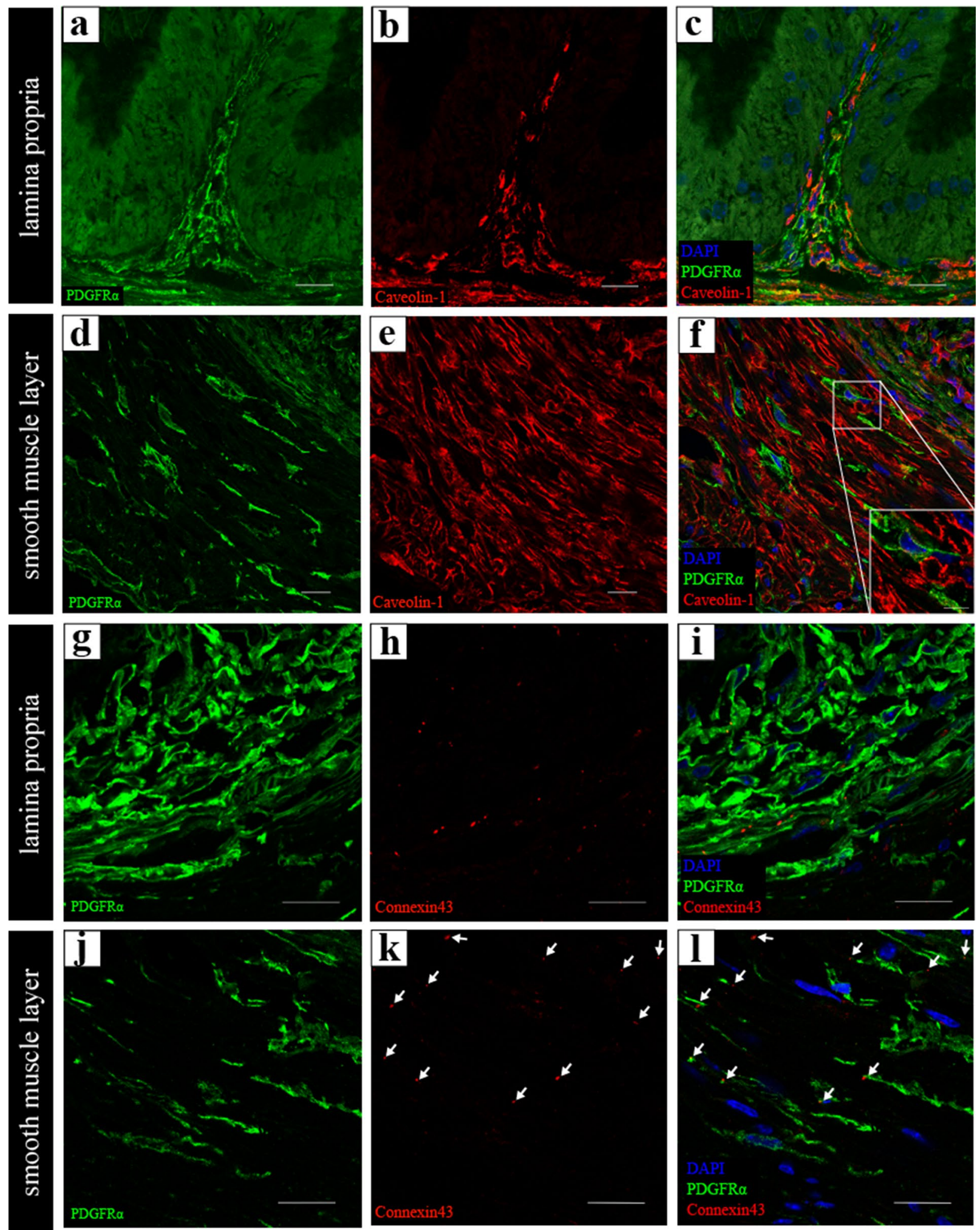

Figure 4. (a-e) Representative images of the double immunolabeling for PDGFRa (green) and caveolin-1 (red) in the lamina propria $(\mathbf{a}-\mathbf{c})$ and in the smooth muscle layer $(\mathbf{b}-\mathbf{e})$. PDGFRa-immunoreactivity (IR) was partially co-labeled with caveolin-1-IR in all layers (c,f). High magnification in the white line square area (inset at the lower right corner of (f)). (g-l) Representative images of the double immunolabeling for PDGFRa (green) and connexin-43 (red) in the lamina propria (g-i) and in the smooth muscle layer $(\mathbf{j}-\mathbf{l})$. Connexin 43-IR was observed surrounding PDGFRa-IR in the lamina propria (i). However, Connexin 43-IR (white arrows) was less prominent in the smooth muscle layer than in the lamina propria (1). Nuclei were counterstained in blue with 4',6-diamidino-2-phenylindole $(\mathbf{c}, \mathbf{f}, \mathbf{i}, \mathbf{l})$. Scale bars: $20 \mu \mathrm{m}(\mathbf{a}-\mathbf{l}), 5 \mu \mathrm{m}$ (inset at the lower right corner of $(\mathbf{f})$ ). 
Figure 5. (a,b) Representative images of the double immunolabeling for PDGFRa (green) and $\alpha$-smooth muscle actin (aSMA; red) in the lamina propria (a) and in the smooth muscle layer (b). PDGFRaimmunoreactivity (IR) was observed around vascular smooth muscle cells labeled with aSMA-IR in the lamina propria (a). Vascular smooth muscle cells were indistinguishable from smooth muscle cells in the smooth muscle layer (b). (c,d): Representative images of the double immunolabeling for PDGFRa (green) and $\beta 3$-tubulin (red) in the lamina propria (c) and in the smooth muscle layer (d). Nerves labeled with $\beta 3$-tubulin were observed in close proximity to some PDGFR $\alpha$-IR cells in the lamina propria and smooth muscle layer (c,d). (e,f) Representative images of the double immunolabeling for PDGFRa (green) and ionized calcium-binding adaptor molecule 1 (Iba-1; red) in the lamina propria (e) and in the smooth muscle layer (f). Macrophages labeled with Iba-1 were observed in close proximity to some PDGFRa-IR in the lamina propria and smooth muscle layer same as nerves and blood vessels $(\mathbf{e}, \mathbf{f})$. (g,h) Representative images of the double immunolabeling for PDGFRa (green) and c-Kit (red) in the lamina propria (g) and in the smooth muscle layer (h). c-Kit-IR was not observed in all the layers of the vas deferens except for mast cells (g,h). Scale bars: $20 \mu \mathrm{m}$ $(\mathbf{a}-\mathbf{h})$.

homogeneously labeled most cytoplasm of ICs in the lamina propria and smooth muscle layer (Fig. 8b,d). This finding was the same as that of immunolabeling (Fig. 2d).

\section{Discussion}

To the best of our knowledge, this is the first study to demonstrate the immunohistochemical, morphological, and ultrastructural characteristics of PDGFRa-positive ICs in mammalian vas deferens. As a preliminary step towards analyzing PDGFRa-ICs, we successfully obtained stereoscopic whole imaging data of murine vas deferens using a modified tissue clearing CUBIC method to determine the target segments. Since the vas deferens contains large amounts of myoglobin, we chose the CUBIC system that efficiently facilitates the decolorization of endogenous chromophores, such as myoglobin, within tissues ${ }^{23}$.

Our 3D reconstruction of the GFP transgenic murine vas deferens illustrated well-developed transverse folds towards the lumen in addition to the previously reported longitudinal folds $s^{24,25}$. The transverse folds appeared more frequent and were winding in a zigzag pattern to fill the luminal space and simultaneously rose towards the distal portion of the organ. The epithelium of the folds expanded and tightly occupied the luminal space, which might have been beneficial in enlarging the surface area to interact with contents, such as sperm and the surrounding fluid, for their metabolism, as well as the phagocytic activity of epithelial cells ${ }^{26,27}$. The structure of vas deferens changes greatly depending on the segment, and the contractions of the circular and longitudinal muscles of the vas deferens have different mechanisms ${ }^{28}$. For further investigation, we selected the distal segment, which had two types of muscularis as well as many complex structures.

Immunohistochemical analyses revealed that PDGFRa-positive ICs were present in the lamina propria, smooth muscle layer, and serosal layer of the murine vas deferens, and may have two different types of immunohistochemical characteristics in the lamina propria. CD34 has been widely used as a marker for labeling interstitial cells, such as PDGFRa and previous studies on other organs have reported that PDGFRa and CD34 are co-labeled frequently ${ }^{29-31}$, however, we found PDGFRa-single positive ICs beneath the epithelium and PDGFRa/CD34-double-positive ICs in the deeper portion. Vannucchi et al. reported that PDGFRa-positive ICs in the upper lamina propria of the human bladder were CD34 negative and PDGFR $\alpha$ positive-ICs in the deep lamina propria, whereas in the detrusor of the human bladder they were CD34-positive ${ }^{32}$. In addition, they reported that some of PDGFRa-positive ICs were also aSMA positive, referred to as 'myoid' ICs ${ }^{32}$, which are thought to be present in the interstitial space of organs in the urinary system, such as kidney and urinary bladder ${ }^{32,33}$. The PDGFR $\alpha / \alpha$-SMA double immunostaining did not reveal 'myoid' ICs in the murine vas deferens stromal compartment. It remains unknown whether the difference in immunochemical characteristics between PDGFR $\alpha$-positive ICs beneath the epithelium and other PDGFR $\alpha$-positive ICs is associated with functional characteristics, however, Shoshkes-Carmel et al. reported that PDGFRa-positive ICs beneath the epithelium in the gastrointestinal tract are an important source of niche signals to intestinal stem cells ${ }^{34}$. Functional significance of the differences in immunostaining patterns of the murine vas deferens, as seen in the gastrointestinal tract, warrants further investigation.

Previous studies in other organs have reported that PDGFRa and vimentin are co-labeled frequently ${ }^{8}$. In the present study, vimentin was labeled primarily in the cell body of PDGFRa-positive ICs and was partially labeled in the prolongations of PDGFRa-positive ICs. These findings indicate that the amount of intermediate filament, labeled by vimentin, is heterogeneous in the cell. Therefore, it is essential to distinguish between vimentinpositive or negative cells, based on the stained section, when conducting immunolabeling ${ }^{35}$.

The ICC of the gastrointestinal tracts express c-Kit. KIT, a receptor tyrosine-protein kinase, acts as a cellsurface receptor for the cytokine KIT ligand/stem cell factor (SCF) and plays an essential role in the regulation of cell survival and proliferation, differentiation, stem cell maintenance, and mast cell development ${ }^{36,37}$. In the present study, c-Kit-positive ICC were not observed. The presence of ICC networks in non-intestinal organs remains controversial. KIT is expressed in several cell types, such as mast cells, hematopoietic cells, spermatogonia, and melanocytic cells ${ }^{38}$. Of these populations, mast cells appear in most of the organs ${ }^{39}$; therefore, c-Kit-positive cells observed in this study were considered as mast cells based on their morphology. However, double staining for c-Kit and the mast cell tryptase is required for a definite identification of c-KIT-positive cells as mast cells.

We observed that PDGFRa-positive ICs in the murine vas deferens were not only in close proximity to each other but also with various cells and tissues including epithelial cells, nerves, vascular endothelial cells, macrophages, and smooth muscle cells, which were seen using immunofluorescence and TEM. According to 


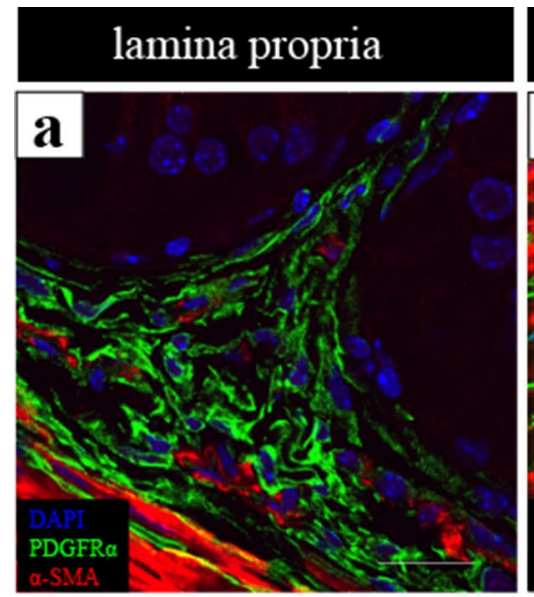

smooth muscle layer
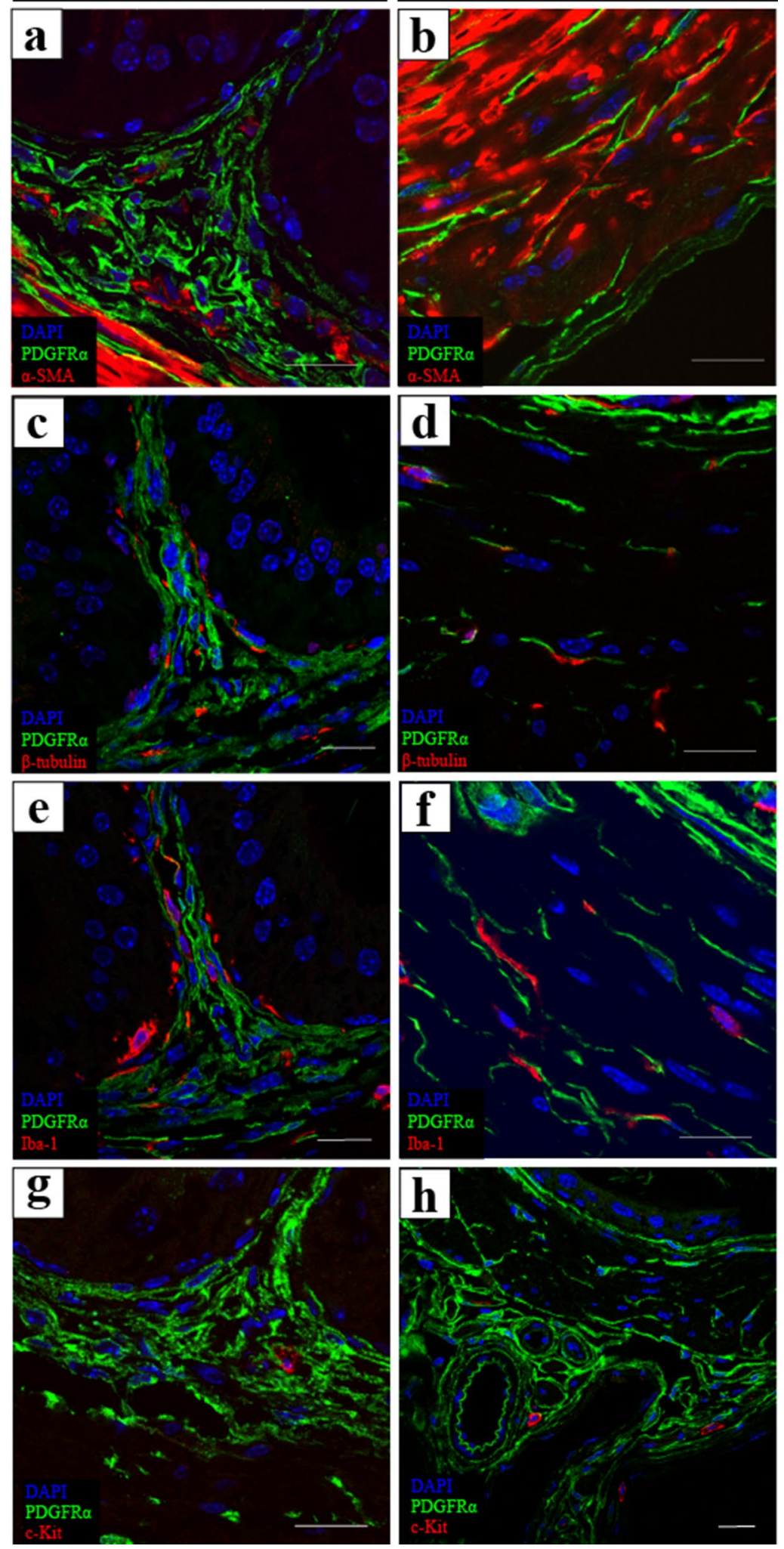

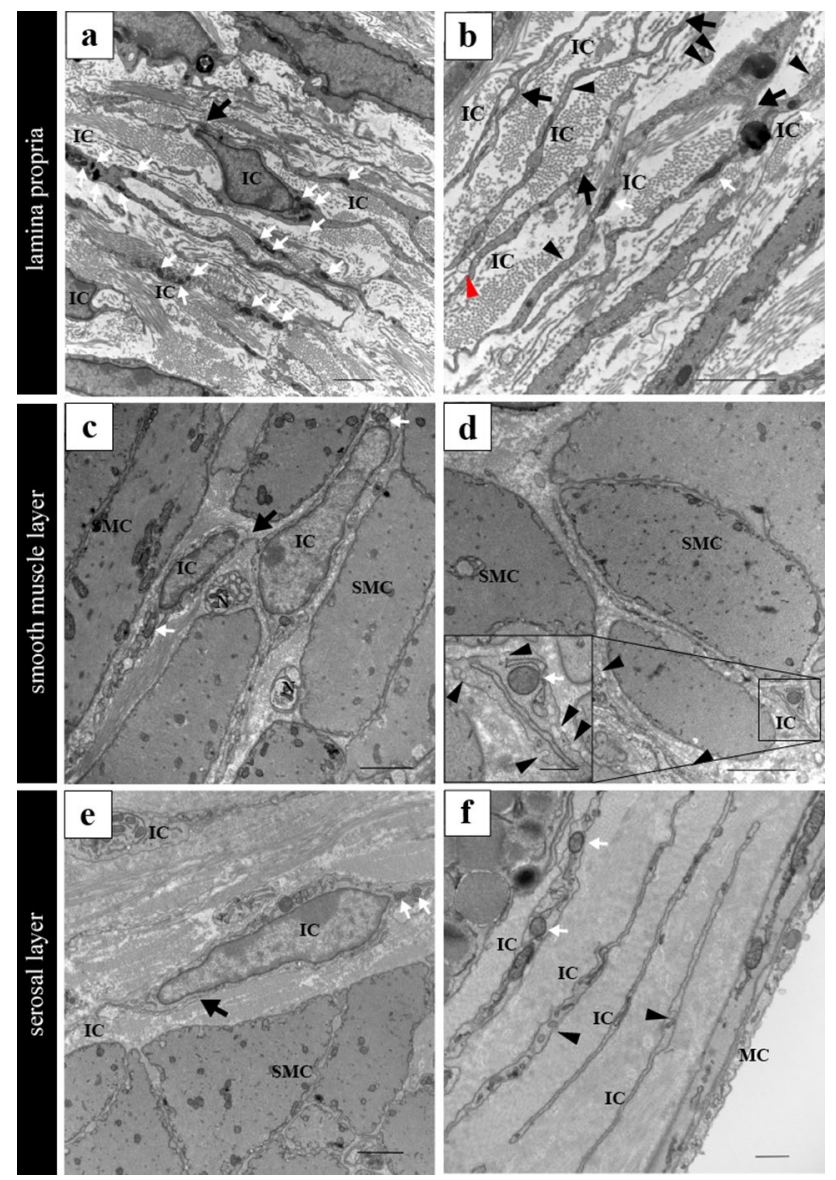

Figure 6. (a) ICs in the lamina propria of the vas deferens. (b) Cell processes of ICs in the lamina propria. Exosome-like structure between cell processes of ICs (red arrowhead). (c) ICs in the smooth muscle layer of the vas deferens. (d) Cell processes of ICs in the smooth muscle layer. High magnification of the solid black line square area (inset at the lower left corner of (d)). (e) ICs in the serosal layer of the vas deferens. (f) Cell processes of ICs in the serosal layer. ICs' cell bodies are relatively small, with sparse cytoplasm containing several mitochondria surrounding the nucleus (white arrows). ICs were in close proximity to each other (black arrows). Caveolae in the cytoplasm of ICs in all the layers (black arrowheads). IC, interstitial cells; SMC, smooth muscle cells; E, epithelium; MC, mesothelial cells. Scale bars: $2 \mu \mathrm{m}(\mathbf{a}-\mathbf{e}) ; 500 \mathrm{~nm}(\mathbf{f}$, inset at the lower left corner of (d)).

previous reports, PDGFRa-positive ICs establish a 3D network of cell processes, and PDGFRa-positive ICs may be involved in nervous, vascular and immune systems, regulation of tissue homeostasis and long-distance communication through intercellular signaling due to their strategic position near other cells and tissues ${ }^{40}$. Our results were consistent with these findings, and PDGFRa-positive ICs in murine vas deferens may also be involved in intercellular signaling.

PDGFRa-positive ICs in the smooth muscle layers of the gastrointestinal tract express the SK3 channel, which plays a critical role in purinergic nerve-mediated smooth muscle relaxation ${ }^{12,13}$. SK3/PDGFR $\alpha$-positive ICs have also been identified in the smooth muscle layers of bladder ${ }^{15}$ and seminal vesicle ${ }^{20}$. In addition, the ANO1 channel is expressed in PDGFRa-positive ICs of renal pelvis where it may influence their spontaneous activities ${ }^{14}$. In the present study, neither SK3 nor ANO-1 channels were detected in the PDGFRa-positive ICs of the smooth muscle layer of the murine vas deferens. The properties of antibodies used, animal species, and organs might have contributed to this.

A small number of caveolae were partially observed in the PDGFRa-positive ICs of murine vas deferens in the EM observations. Although the role of the caveolae of PDGFRa-positive ICs remains unclear, ICCs of the myenteric plexus have been reported to account for the recycling of calcium from caveolar domains to SR through Cav1 to sustain pacing and contractions ${ }^{41}$. In addition, gap junctions between PDGFRa-positive ICs may distribute more frequently in the lamina propria than in the smooth muscle layer depending on the distribution density of ICs. Previous studies have reported that PDGFRa-positive ICs exchange small molecules, so-called secondary molecular messengers with role in cellular signaling, via gap junctions $\mathrm{s}^{42,43}$. No gap junctions were observed between PDGFRa-positive ICs and smooth muscle cells in the murine vas deferens. This finding supports the hypothesis that gap junctions expressed by PDGFRa-positive ICs are restricted to homocellular communications ${ }^{44}$. Connexin 43 does not definitively prove the existence of gap junctions ${ }^{45}$, and the observation of gap junctions with TEM is challenging since gap junctions may only be present in tiny contact areas between the PDGFRa-positive ICs. The 2-3 nm "gap" separating the plasma membranes is commonly observed in a 

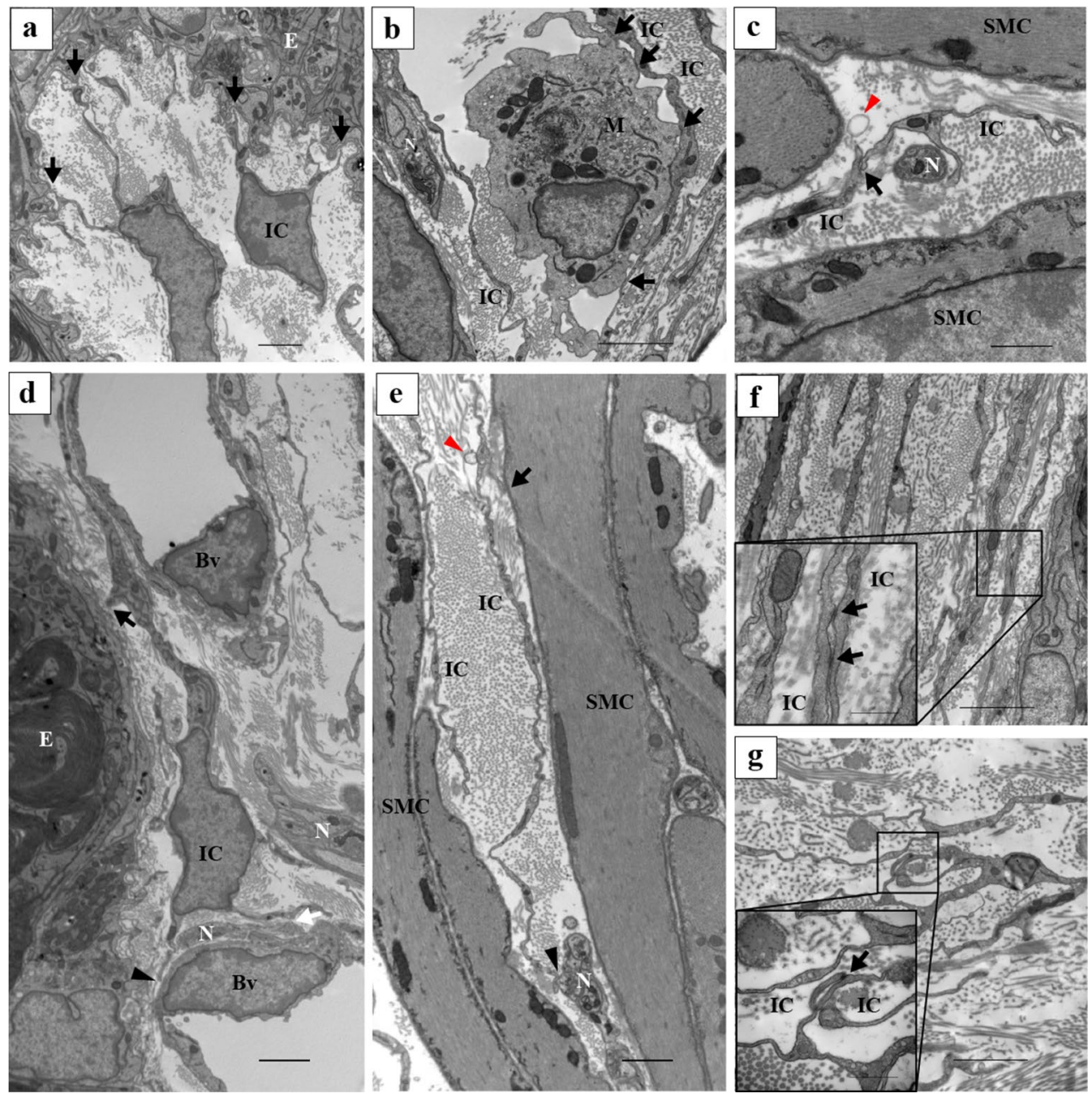

Figure 7. (a) The cell processes of the ICs were in close proximity to the epithelium (black arrows). (b) A cell process of the IC was close proximity to a macrophage (black arrows). A cell process of the IC wraps nerves and the close proximity to the cell process of the other IC (black arrows). (c) Exosome-like structure nearby cell process of the IC (red arrowhead). (d) The IC in the lamina propria were close proximity to surrounding tissues. The IC in the lamina propria was in close proximity to the epithelial cell (black arrow), a vascular endothelial cell (black arrowhead) and a nerve (white arrow). (e) The IC in the smooth muscle layer was in close proximity to the surrounding tissues. The IC in the smooth muscle layer was in close proximity to a smooth muscle cell (black arrow) and a nerve (black arrowhead). Exosome-like structure near the cell processes of IC (red arrowhead). (f,g) TEM images of contact areas between ICs. Higher magnification of the solid black line square area (inset at the lower left corner of $(\mathbf{f}, \mathbf{g})$ ). Electron-dense lines exist in the contact area between ICs (black arrows). IC, interstitial cells; E, epithelium; N, nerves; Bv, blood vessels; M, macrophages. Scale bars: $2 \mu \mathrm{m}(\mathbf{a}-\mathbf{g})$; $500 \mu \mathrm{m}$ (inset at the lower left corner of $(\mathbf{f}, \mathbf{g})$ ).

high magnification view of the gap junction ${ }^{43}$. However, it is difficult to observe the "gap" in tiny contact areas between PDGFRa-positive ICs. Therefore, further investigations are warranted to elucidate the possible role of gap junctions in murine vas deferens.

We frequently identified fragmented vesicles, microvesicle-like structures or exosomes, between PDGFRapositive ICs and surrounding tissues in our TEM images. It is possible that PDGFRa-positive ICs were supposed to transfer functional molecules to surrounding tissues and cells by exosomes. The term "stromal synapse" has been used to describe synaptic connections between PDGFRa-positive ICs and neighboring cells, speculated as a juxtracrine (a chemical synapse) and corresponding to an exosome-based mechanism ${ }^{46}$. The exosomes may act as specific containers filled with proteins, lipids, microRNA, and/or other materials that are transported to other neighboring stromal cells where they alter their function ${ }^{47}$. These vesicles transport RNA or DNA to target cells, inducing epigenetic changes ${ }^{48}$. Therefore, further research on exosome-like structures observed in the present study may demonstrate the function of PDGFRa-positive ICs.

Our study has three limitations. First, PDGFRa, as a cell marker, may also label various mesenchymal cells. Therefore, use of several antibodies can increase the immunohistochemical discrimination. Second, our findings and previous studies related to the morphological evaluation of PDGFRa-positive ICs have mostly used 2D images obtained from sections ${ }^{18,29,30,49}$. As PDGFRa-positive ICs are very elongated, and their cell processes 


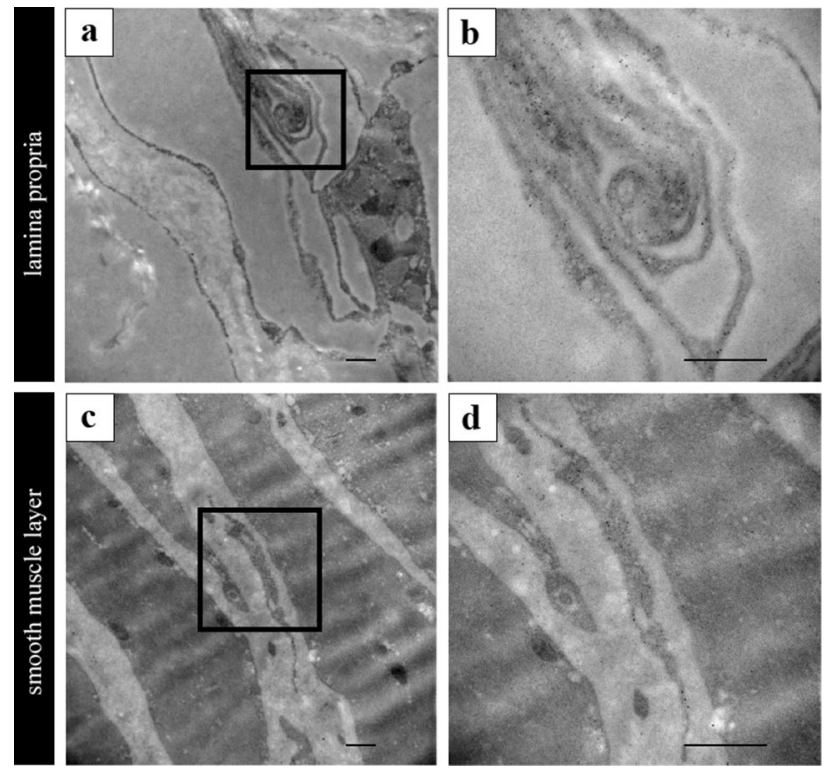

Figure 8. (a-d) Immunoelectron microscopy revealed ICs labeled PDGFRa in the lamina propria and smooth muscle layer. (b) High magnification of the solid black line square area in (a). (d) High magnification of the solid black square area in (c). A total of $10 \mathrm{~nm}$ colloidal golds homogeneously labeled in the cytoplasm of ICs (b,d). Scale bars: $2 \mu \mathrm{m}(\mathbf{a}, \mathbf{c}) ; 500 \mathrm{~nm}(\mathbf{b}, \mathbf{d})$.

multi-branched, the 3D evaluation would increase the accuracy of identifying such morphological changes. Visualization of GFP-positive cells in the 3D organ architecture by CUBIC method used in the present study is one of the choices to reveal 3D structure of PDGFRa-positive ICs. Finally, PDGFRa-positive ICs observed by CLSM are different from TEM observed cells. By a correlative light and electron microscopy (CLEM) method, more accurate ultrastructural information of PDGFRa-positive ICs can be obtained as the same cell samples are investigated using both light and electron microscopy.

In conclusion, our findings suggest that PDGFRa-positive ICs were located in the lamina propria, smooth muscle, and serosal layers of the murine vas deferens. In addition, PDGFRa-positive ICs may have several subpopulations depending on localization from immunohistochemical characteristics. Although we did not elucidate the presumptive functions of PDGFRa-positive ICs in murine vas deferens; they may however play an important role in intercellular signaling via direct contact of the IC network and extracellular vesicles, similar to previous reports on other organs. This study provides a novel structural and functional perspective on the cellular components of murine vas deferens. Our findings also progress our understanding of the physiological aspects of vas deferens. Further investigations on PDGFRa-positive ICs of the vas deferens may lead to understanding vas deferens motility.

\section{Data availability}

All data generated or analyzed in this study are included in this article and the Supplementary Information Files.

Received: 20 August 2020; Accepted: 23 March 2021

Published online: 06 April 2021

\section{References}

1. Berridge, M. J. Smooth muscle cell calcium activation mechanisms. J. Physiol. 586, 5047-5061. https://doi.org/10.1113/jphysiol. 2008.160440 (2008).

2. Koslov, D. S. \& Andersson, K. E. Physiological and pharmacological aspects of the vas deferens-an update. Front. Pharmacol. 4, 101. https://doi.org/10.3389/fphar.2013.00101 (2013).

3. Hagger, R., Finlayson, C., Jeffrey, I. \& Kumar, D. Role of the interstitial cells of Cajal in the control of gut motility. Br. J. Surg. 84, $445-450$ (1997).

4. Zhang, R. X., Wang, X. Y., Chen, D. \& Huizinga, J. D. Role of interstitial cells of Cajal in the generation and modulation of motor activity induced by cholinergic neurotransmission in the stomach. Neurogastroenterol. Motil. 23, e356-371. https://doi.org/10. 1111/j.1365-2982.2011.01753.x (2011).

5. Ward, S. M., Sanders, K. M. \& Hirst, G. D. Role of interstitial cells of Cajal in neural control of gastrointestinal smooth muscles. Neurogastroenterol. Motil. 16(Suppl 1), 112-117. https://doi.org/10.1111/j.1743-3150.2004.00485.x (2004).

6. Sanders, K. M. Interstitial cells of Cajal at the clinical and scientific interface. J. Physiol. 576, 683-687. https://doi.org/10.1113/ jphysiol.2006.116814 (2006).

7. Komuro, T. Comparative morphology of interstitial cells of Cajal: Ultrastructural characterization. Microsc. Res. Tech. 47, 267-285. https://doi.org/10.1002/(SICI)1097-0029(19991115)47:4\%3c267::AID-JEMT5\%3e3.0.CO;2-O (1999).

8. Aleksandrovych, V. et al. Telocytes: Facts, speculations and myths (Review article). Folia. Med. Cracov. 57, 5-22 (2017).

9. Andrae, J., Gallini, R. \& Betsholtz, C. Role of platelet-derived growth factors in physiology and medicine. Genes Dev 22, 1276-1312. https://doi.org/10.1101/gad.1653708 (2008). 
10. Edelstein, L. \& Smythies, J. The role of telocytes in morphogenetic bioelectrical signaling: Once more unto the breach. Front. Mol. Neurosci. 7, 41. https://doi.org/10.3389/fnmol.2014.00041 (2014).

11. Mirancea, N. Telocyte-a particular cell phenotype. Infrastructure, relationships and putative functions. Rom. J. Morphol. Embryol. 57, 7-21 (2016).

12. Baker, S. A., Hennig, G. W., Ward, S. M. \& Sanders, K. M. Temporal sequence of activation of cells involved in purinergic neurotransmission in the colon. J. Physiol. 593, 1945-1963. https://doi.org/10.1113/jphysiol.2014.287599 (2015).

13. Kurahashi, M. et al. A functional role for the "fibroblast-like cells" in gastrointestinal smooth muscles. J. Physiol. 589, 697-710. https://doi.org/10.1113/jphysiol.2010.201129 (2011).

14. Grainger, N. et al. Identification and classification of interstitial cells in the mouse renal pelvis. J. Physiol. https://doi.org/10.1113/ JP278888 (2020).

15. Lee, H., Koh, B. H., Peri, L. E., Sanders, K. M. \& Koh, S. D. Functional expression of SK channels in murine detrusor PDGFR+ cells. J. Physiol. 591, 503-513. https://doi.org/10.1113/jphysiol.2012.241505 (2013).

16. Yang, C. \& Xiao, J. Editorial: Telocytes in regeneration and repair. Curr. Stem Cell Res. Ther. 11, 382. https://doi.org/10.2174/15748 $88 \times 1105160509233334(2016)$.

17. Varga, I. et al. Recently discovered interstitial cell population of telocytes: Distinguishing facts from fiction regarding their role in the pathogenesis of diverse diseases called "Telocytopathies". Medicina https://doi.org/10.3390/medicina55020056 (2019).

18. Liu, Y. et al. Identification and characterization of telocytes in rat testis. Aging (Albany NY) 11, 5757-5768. https://doi.org/10. 18632/aging.102158 (2019).

19. Awad, M. \& Ghanem, M. E. Localization of telocytes in rabbits testis: Histological and immunohistochemical approach. Microsc. Res. Tech. 81, 1268-1274. https://doi.org/10.1002/jemt.23133 (2018).

20. Takeya, M. et al. Role of mucosa in generating spontaneous activity in the guinea pig seminal vesicle. J. Physiol. 595, 4803-4821. https://doi.org/10.1113/JP273872 (2017).

21. Okabe, M., Ikawa, M., Kominami, K., Nakanishi, T. \& Nishimune, Y. "Green mice" as a source of ubiquitous green cells. FEBS Lett. 407, 313-319. https://doi.org/10.1016/s0014-5793(97)00313-x (1997).

22. Walton, J. Lead aspartate, an en bloc contrast stain particularly useful for ultrastructural enzymology. J. Histochem. Cytochem. 27, 1337-1342. https://doi.org/10.1177/27.10.512319 (1979).

23. Susaki, E. A. \& Ueda, H. R. Whole-body and whole-organ clearing and imaging techniques with single-cell resolution: Toward organism-level systems biology in mammals. Cell Chem. Biol. 23, 137-157. https://doi.org/10.1016/j.chembiol.2015.11.009 (2016).

24. Kennedy, S. W. \& Heidger, P. M. Fine structural studies of the rat vas deferens. Anat. Rec. 194, 159-179. https://doi.org/10.1002/ ar.1091940111 (1979).

25. Prins, G. S. \& Zaneveld, L. J. Distribution of spermatozoa in the rabbit vas deferens. Biol. Reprod. 21, 181-185. https://doi.org/10. 1095/biolreprod21.1.181 (1979).

26. Murakami, M., Nishida, T., Iwanaga, S. \& Shiromoto, M. Scanning and transmission electron microscopic evidence of epithelial phagocytosis of spermatozoa in the terminal region of the vas deferens of the cat. Experientia 40, 958-960. https://doi.org/10. 1007/BF01946458 (1984).

27. Cooper, T. G. \& Hamilton, D. W. Phagocytosis of spermatozoa in the terminal region and gland of the vas deferens of the rat. Am. J. Anat. 150, 247-267. https://doi.org/10.1002/aja.1001500204 (1977).

28. Amobi, N. I., Guillebaud, J. \& Smith, I. C. Perspective on the role of P2X-purinoceptor activation in human vas deferens contractility. Exp. Physiol. 97, 583-602. https://doi.org/10.1113/expphysiol.2011.063206 (2012).

29. Vannucchi, M. G., Traini, C., Manetti, M., Ibba-Manneschi, L. \& Faussone-Pellegrini, M. S. Telocytes express PDGFRa in the human gastrointestinal tract. J. Cell Mol. Med. 17, 1099-1108. https://doi.org/10.1111/jcmm.12134 (2013).

30. Rosa, I. et al. Telocytes constitute a widespread interstitial meshwork in the lamina propria and underlying striated muscle of human tongue. Sci. Rep. 9, 5858. https://doi.org/10.1038/s41598-019-42415-3 (2019).

31. Rosa, I., Marini, M., Sgambati, E., Ibba-Manneschi, L. \& Manetti, M. Telocytes and lymphatic endothelial cells: Two immunophenotypically distinct and spatially close cell entities. Acta Histochem. 122, 151530. https://doi.org/10.1016/j.acthis.2020.151530 (2020).

32. Vannucchi, M. G., Traini, C., Guasti, D., Del Popolo, G. \& Faussone-Pellegrini, M. S. Telocytes subtypes in human urinary bladder. J. Cell Mol. Med. 18, 2000-2008. https://doi.org/10.1111/jcmm.12375 (2014).

33. Desmoulière, A., Darby, I. A. \& Gabbiani, G. Normal and pathologic soft tissue remodeling: Role of the myofibroblast, with special emphasis on liver and kidney fibrosis. Lab. Invest. 83, 1689-1707. https://doi.org/10.1097/01.lab.0000101911.53973.90 (2003).

34. Shoshkes-Carmel, M. et al. Subepithelial telocytes are an important source of Wnts that supports intestinal crypts. Nature 557, 242-246. https://doi.org/10.1038/s41586-018-0084-4 (2018).

35. Koh, B. H. et al. Platelet-derived growth factor receptor- $\alpha$ cells in mouse urinary bladder: A new class of interstitial cells. J. Cell Mol. Med. 16, 691-700. https://doi.org/10.1111/j.1582-4934.2011.01506.x (2012).

36. Kitamura, Y. \& Hirotab, S. Kit as a human oncogenic tyrosine kinase. Cell Mol. Life Sci. 61, 2924-2931. https://doi.org/10.1007/ s00018-004-4273-y (2004).

37. Stankov, K., Popovic, S. \& Mikov, M. C-KIT signaling in cancer treatment. Curr. Pharm. Des. 20, 2849-2880. https://doi.org/10. 2174/13816128113199990593 (2014).

38. Huizinga, J. D. \& Chen, J. H. Interstitial cells of Cajal: Update on basic and clinical science. Curr. Gastroenterol. Rep. 16, 363. https:// doi.org/10.1007/s11894-013-0363-z (2014).

39. Stone, K. D., Prussin, C. \& Metcalfe, D. D. IgE, mast cells, basophils, and eosinophils. J. Allergy Clin. Immunol. 125, S73-80. https:// doi.org/10.1016/j.jaci.2009.11.017 (2010).

40. Gherghiceanu, M. \& Popescu, L. M. Cardiac telocytes-their junctions and functional implications. Cell Tissue Res. 348, $265-279$. https://doi.org/10.1007/s00441-012-1333-8 (2012).

41. Daniel, E. E., Eteraf, T., Sommer, B., Cho, W. J. \& Elyazbi, A. The role of caveolae and caveolin 1 in calcium handling in pacing and contraction of mouse intestine. J. Cell Mol. Med. 13, 352-364. https://doi.org/10.1111/j.1582-4934.2008.00667.x (2009).

42. Faussone-Pellegrini, M. S. \& Gherghiceanu, M. Telocyte's contacts. Semin. Cell Dev. Biol. 55, 3-8. https://doi.org/10.1016/j.semcdb. 2016.01.036 (2016).

43. Goodenough, D. A. \& Paul, D. L. Gap junctions. Cold Spring Harb. Perspect. Biol. 1, a002576. https://doi.org/10.1101/cshperspect. a002576 (2009).

44. Popescu, L. M., Fertig, E. T. \& Gherghiceanu, M. Reaching out: Junctions between cardiac telocytes and cardiac stem cells in culture. J. Cell Mol. Med. 20, 370-380. https://doi.org/10.1111/jcmm.12719 (2016).

45. Laird, D. W. Life cycle of connexins in health and disease. Biochem. J. 394, 527-543. https://doi.org/10.1042/BJ20051922 (2006).

46. Popescu, L. M., Gherghiceanu, M., Cretoiu, D. \& Radu, E. The connective connection: Interstitial cells of Cajal (ICC) and ICC-like cells establish synapses with immunoreactive cells. Electron microscope study in situ. J. Cell Mol. Med. 9, 714-730. https://doi.org/ 10.1111/j.1582-4934.2005.tb00502.x (2005).

47. El-Tahawy, N. F. G. \& Rifaai, R. A. Immunohistochemical and ultrastructural evidence for telocytes in the different physiological stages of the female rat mammary gland. Life Sci. 231, 116521. https://doi.org/10.1016/j.lfs.2019.05.077 (2019).

48. Yang, P. et al. Cellular evidence of telocytes as novel interstitial cells within the magnum of chicken oviduct. Cell Transplant. 26, 135-143. https://doi.org/10.3727/096368916X692942 (2017). 
49. Marini, M. et al. Telocytes in normal and keratoconic human cornea: An immunohistochemical and transmission electron microscopy study. J. Cell Mol. Med. 21, 3602-3611. https://doi.org/10.1111/jcmm.13270 (2017).

\section{Acknowledgements}

The authors wish to thank Ms. Risa Tuneyoshi for technical assistance. This study was supported by a JSPS Grantin-Aid for Scientific Research (B) (Grant Number 20H03290).

\section{Author contributions}

T.H. designed the study, performed the experiments (data acquisition and analysis), and revised the manuscript. K.U., S.H., K.H., A.T., K.O., and K.N. contributed to the experiments (data acquisition and analysis) and revised the manuscript. K.U. and T.I. contributed to data interpretation and revised the manuscript. All the authors independently reviewed the manuscript.

\section{Competing interests}

The authors declare no competing interests.

\section{Additional information}

Supplementary Information The online version contains supplementary material available at https://doi.org/ 10.1038/s41598-021-87049-6.

Correspondence and requests for materials should be addressed to T.H.

Reprints and permissions information is available at www.nature.com/reprints.

Publisher's note Springer Nature remains neutral with regard to jurisdictional claims in published maps and institutional affiliations.

(c) (i) Open Access This article is licensed under a Creative Commons Attribution 4.0 International License, which permits use, sharing, adaptation, distribution and reproduction in any medium or format, as long as you give appropriate credit to the original author(s) and the source, provide a link to the Creative Commons licence, and indicate if changes were made. The images or other third party material in this article are included in the article's Creative Commons licence, unless indicated otherwise in a credit line to the material. If material is not included in the article's Creative Commons licence and your intended use is not permitted by statutory regulation or exceeds the permitted use, you will need to obtain permission directly from the copyright holder. To view a copy of this licence, visit http://creativecommons.org/licenses/by/4.0/.

(c) The Author(s) 2021 